\title{
OPTIMIZING THE URBAN THERMAL ENVIRONMENT AT LOCAL SCALE: A CASE STUDY IN WUHAN, CHINA
}

\author{
YAFEI YUE ${ }^{1,2}$, QINGMING ZHAN*,1,2, JIONG WANG ${ }^{1,2}$ \& YINGHUI XIAO ${ }^{1,2}$ \\ ${ }^{1}$ School of Urban Design, Wuhan University, China. \\ ${ }^{2}$ Collaborative Innovation Center of Geospatial Technology, Wuhan, China.
}

\begin{abstract}
The urban thermal environment deteriorates with increasing frequency of extreme heat events in cities. Conventionally, the Urban Heat Island (UHI) effect only reflects the temperature difference between the city and its rural surroundings. This scale of analysis is often too broad to help devise mitigation strategies, which are typically implemented at a more local scale within the sphere of urban planning and design. In this research, the city of Wuhan, China, is taken as an example. Through quantitative measurements, a workflow is proposed to mitigate the surface UHI of Wuhan, locally. Also, the satellite images of the MODerate-resolution Imaging Spectroradiometer and Landsat-7 ETM+ are used for technical purposes, and the K-means clustering is applied to classify the Local Climate Zone (LCZ). Further, the Local Scale Urban Heat Island (LSUHI) is captured through morphological parameters, such as Multi-Scale Shape Index (MSSI) based upon the latent Land Surface Temperature (LST) pattern. The mitigation process is organized hierarchically and prioritized by the combination of LCZ and LSUHI. Based on this, Wuhan is divided into seven LCZs and the LSUHI, in the mean time, can be detected by morphological parameters. We present the corresponding quantitative planning advice for places with higher heat threats in the city. This research is conducted on urban microclimate and urban planning on at least two levels: (1) the reduced study scale of urban thermal environment and (2) a planning-driven workflow of urban thermal environment optimization.

Keywords: climate zone, heat island, hotspot, land surface temperature, local scale, morphology.
\end{abstract}

\section{INTRODUCTION}

Global temperature continues to rise and cities may possess higher warming rates than natural land covers [1]. The phenomenon of higher temperature in urban areas is known as the Urban Heat Island (UHI). The physical mechanisms through which the UHI effect is driven are well documented. Primary constituents of urban construction, such as asphalt, cement, and roofing tiles, have a much greater heat capacity than forest vegetation and other natural features [2]. The enhanced anthropogenic heat emissions, reduced evaporative cooling, increased surface roughness, lower surface albedos and narrow urban canyon geometry associated with cities also results in the formation of UHIs [3].

Tragic socio-economic consequences of urban heat events have been realized and addressed only lately. Most cities are reported to be without any form of regulations for temperature mitigation in terms of land surface management [4]. Even at the local level, some climate action plans that only considered greenhouse gas emission control were insufficient to address the problem [1].

\subsection{The land surface specification in the local climate zones}

One of the significant weaknesses of current research on microclimate is the lack of standards, which impedes both the quantitative measurement of meteorology phenomenon at a local scale and the development of local meteorological research of urban climate [5]. Most planning and design concepts are restricted by lack of quantitative standards that can mitigate and adapt climate uncertainties [1]. The weakness is quite intuitive in the study of 
temperature patterns and variations at the local scale [6]. Building upon the concept of Urban Climate Zone (UCZ) and Local Climate Zone (LCZ) initiated by Oke's (2011) research team, the research applies the idea to an entire city [7]. The LCZ is proposed such that the study of microclimate can be set into a standard background. The framework of LCZ recommends that the land surface should be classified into zones quantitatively according to their meteorological responses. The classification indicators include the surface material and meteorological properties. This can be further defined according to the surface configuration of a natural and a built environment, such as Impervious Surface Fraction (ISF) or Pervious Surface Fraction (PSF) [8-10], albedo [11-13], Sky View Factor (SVF) [14-16], the vegetation fraction [8, 17-19], and building density [2, 20].

The LCZ is a framework that has been proposed recently, and has been validated through circling places with radius of hundreds of meters in few cities [21]. The application of the concept is rarely found. Szeged, Hungary, began to apply the framework to the whole city in 2014 [22]. More applications and tests of the framework are needed to bring insights of the dynamics of local climate at the local scale.

\subsection{Characterizing the surface urban heat Island}

Conventionally, UHI is defined as the temperature difference between urban and rural areas. The investigations are largely influenced by the conventional 'urban-rural' dichotomy at the city scale [5]. The analyses of UHI aim at urban surface with remote sensing data and the findings of the specific relation between Land Surface temperature (LST) and air temperature [20]. LST became the primary concern because it governs the energy balance at the lowest layer of the atmosphere in the urban areas and controls the air temperature within the Urban Canopy Layer (UCL) [23]. When the temperature study boils down to investigate the LST within the UCL, UHI accordingly became the Surface Urban Heat Island (SUHI). A milestone is the characterization of the city scale SUHI of Houston, Texas, USA, by applying the unimodal Gaussian surface to the fitting of the Advanced Very High Resolution Radiometer (AVHRR) image data [24]. An extension of the methodology is employing the non-parametric kernel method to model the LST and SUHI patterns in Indianapolis, Indiana, USA [25].

\subsection{Research framework}

Since the classification of LCZs is based upon a set of indicators that reflect certain meteorological properties of the study area, the LCZs provide a configuration of climatic ingredients of the area and depict how the climatic patterns of the area distribute locally. Based on the modified version of the Stewart's (2011) LCZ scheme with a focus on LST, 9 LST-sensitive indicators are extracted from land surface factors and are used as the basis of classification for climate zones in Wuhan.

Based on the previous research of SUHI, the LST is further delineated with a combination of spatial and morphological information. In order to find out the prioritized areas with high temperature locally, the parameters are used as indicators to identify Local Scale Urban Heat Island (LSUHI).

LCZ provides the framework to mitigate LSUHI from the perspective of planning domains in two aspects. Firstly, the scope of LSUHI is limited to a single LCZ, rather than to the whole city. Secondly, the mitigation approaches for LSUHI are based on the classification indicators of LCZ. Then, the quantitative planning strategy is proposed by combining LCZ and LSUHI in hierarchies and priorities (Fig. 1). The research provides a workflow for the improvement 


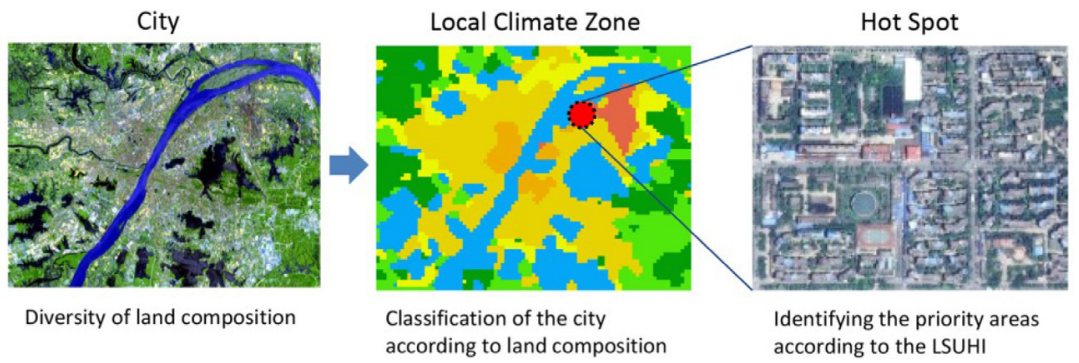

Figure 1: The hierarchical structure and priority for optimizing urban thermal environment.

of urban climate in terms of planning and implementation. The workflow includes the classification of the climate zone, the detection of the hotspot, and the adjustment of relevant land surface parameters.

\section{METHODOLOGY}

\subsection{Study area and data}

Wuhan, China, is selected as the case study. The city is located in central China. It is the fifth most populous city in the nation. Wuhan is characterized by its heterogeneity of land cover. The water bodies scatter within and around the urban area highlighting the diversity of land composition. The extent of the study area is $45 \times 36 \mathrm{~km}$, which covers entire downtown Wuhan and extends to the surrounding rural area. The upper-left and lower-right coordinates are ' $30^{\circ} 43^{\prime} 53^{\prime \prime} \mathrm{N}, 114^{\circ} 4^{\prime} 49^{\prime \prime} \mathrm{E}$ ' and ' $30^{\circ} 24^{\prime} 0^{\prime \prime} \mathrm{N}, 114^{\circ} 32^{\prime} 34^{\prime \prime} \mathrm{E}$ ', respectively. This coverage is sufficient to exhibit the land composition of the city (Fig. 2a). The L1T product with the resolution of 30 meters in 2012 captured by Landsat-7 ETM+ is employed to measure the land surface indicators, including PSF, ISF, albedo, Vegetation Index (VI), Water Index (WI), etc. The indicators including SVF, Building Density (BD), Building Volume Density (BVD), and Building Height (BH), are measured through shapefile of building data in 2012 according to the relevant Wuhan governmental departments. The MODIS/Terra (MOD11A2) and
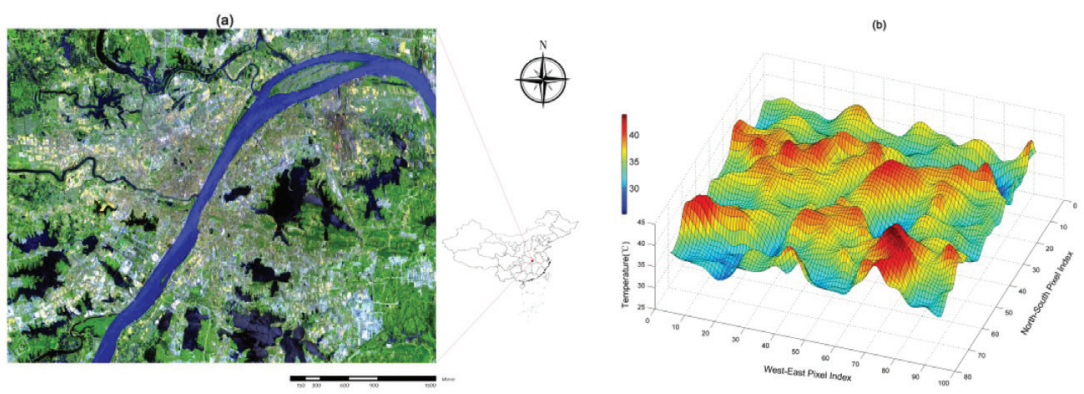

Figure 2: Study area and its latent LST. (a) The study area represented by false color image. SWIR2, NIR, and Green bands of Landsat ETM+ are combined to highlight the land surface heterogeneity of built environment, vegetation, and water bodies. (b) The latent LST at 13:30h, July 27th, 2012, extracted by using Gaussian Process model. 
MODIS/Aqua (MYD11A2) V5 Daily L3 Global $1 \mathrm{~km}$ Grid products in 2012 are used to represent the LST pattern at a particular time point. The MYD11A2 data is acquired at 01:30h and 13:30h local time, and the MOD11 A2 data is acquired at 10:30h and 22:30h local time. The accuracy of the LST data is better than $1 \mathrm{~K}(0.5 \mathrm{~K}$ in most cases $)$. The LST is converted to Celsius degrees in this research. Before analyzing the morphology of LST, the Gaussian Process (GP) model [26] is used to extract the smooth and continuous latent pattern of LST as shown in Fig. $2 b$.

In the study of Wuhan, the variogram of LST at the phenomenon level and multi-scale analysis together define the operational scale of the LST-ISF interaction to be in the range of $500-650 \mathrm{~m}$. The value is reasonable considering the characteristics of Chinese cities [10]. So, the scale of this research for LST and LCZ is set at $500 \mathrm{~m}$.

\subsection{The indicators and classification for the LCZs}

The LCZs are classified in terms of temperature-sensitive indicators extracted from land surface factors. The indicators are selected empirically according to previous investigations of the land surface-LST relationships. For illustration, altogether 9 most frequently used LST sensitive land surface indicators extracted from vegetation, buildings, and land covers are used for classification. The indicators are SVF [27], BD, BVD [28], BH [17], PSF, albedo, VI, ISF, and WI [29]. Specifically, SVF is computed using vector databases based on methodology from Gál [27]; VI is coverage of vegetation and WI is coverage of water, respectively.

The indicators are all unified to the same raster resolution with pixel size of $500 \mathrm{~m}$. The indicators are considered as properties of a certain area of the land surface, which means for each pixel, its properties can be taken as a multi-dimensional vector. In this situation, the $\mathrm{K}$-means clustering is applied for the reason that such classification approach utilizes the intrinsic structure of the data as opposed to artificial partition by using empirical values. In this study, the pixels can be viewed as $n$ observations, and for each observation the properties is a $d$ dimensional vector $P$. All the pixels are in a $d$ dimensional space $\left(P_{1}, P_{2} \ldots P_{\mathrm{n}}\right)$. The $\mathrm{K}$-means clustering separates the pixels into k sets to minimize the within-cluster sum of squares. Thus it tries to find

$$
\arg \min \sum_{i=1}^{k} \sum\left\|\mathbf{p}-\mu_{i}\right\|^{2}
$$

where $\mu_{i}$ is the mean of cluster $i$.

\subsection{The morphological indicators}

The conventional parameters characterizing UHI are restricted to the city or regional scale by the 'urban-rural' dichotomy. This research identifies LSUHI through the morphology of LST at a local scale. The morphological indicators are based on the smooth and continuous latent pattern of the LST, which is derived by the Gaussian Process (GP) model [26]. The MSSI is an extension of Koenderink's Shape Index (SI) [30] that evaluates shapes at the optimal scale. It thus contains two steps: 1) scale selection, and 2) the SI evaluation.

The SI of each pixel should be calculated at its appropriate scale. The scale selection adopts the scale space [31]. The characteristic scale can be found in terms of the kernel size that produces the maximum normalized distance in the scale space. The optimal scale can be 
identified by the maxima normalized distance [32]. Then the MSSI is the SI evaluated at each point on a surface at the optimal scale, which is represented as

$$
M S S I=\frac{2}{\pi} \arctan \frac{\kappa_{2}+\kappa_{1}}{\kappa_{2}-\kappa_{1}}, S I \in[-1,1],
$$

where $\kappa_{1}$ and $\kappa_{2}\left(\kappa_{1} \geq \kappa_{2}\right)$ are the principle curvatures. The principle curvatures can be easily evaluated from a noiseless continuous latent LST surface through eigenvalues of the Hessian matrix. The MSSI measures how a point varies relative to its surroundings as shown in Fig. 3. The deformations are encoded within the interval $[-1,1]$. The value indicates the extent of the deformation along the principle curvatures. Typical shapes such as cup, rut, saddle, ridge, and cap can be measured along the interval. It thus captures both the geometry and the magnitude.

\subsection{Selecting the LSUHI and the local hotspot}

The selection criteria of LSUHI in this research are as follows. The temperature threshold set in each of the LCZs is a 2-standard-deviation from the zonal mean, determining whether LSUHI is excessively hot, and the MSSI $>0$ helps to select the raised LSUHIs. The 8-day MODIS image data represents the daily average monthly LST in 2012. LSUHIs can be selected by the criteria from every latent LST pattern. While four sets of LST images are acquired each day, there is a total of 48 distribution diagrams of LSUHIs during the whole year. The local hotspots are detected, whose frequency is the highest among LSUHIs in each LCZ throughout the year.

\subsection{The LST-responsive land surface indicators}

It is necessary to examine the relationship between LST and land surface indicators in each zone for mitigating the hotspots. The examination may concretely support the existence of the indicator-LST interactions and gives information about how the relationship varies through space. It also indicates the potential LST change by modifying a specific indicator at the percentage level. The examination provides two modules. The temperature responses of SVF, BD, BVD, BH, albedo, VI, and WI are first considered. Then, the temperature response of ISF is considered independently from the rest of the indicators to avoid collinearity [9]. PSF is left out also for its collinearity with ISF. This study applies Ordinary Least Squares (OLS) to inspect the interactions. It is in the form of:

$$
\mathrm{T}_{L S T}=\mathrm{X} \beta+e,
$$

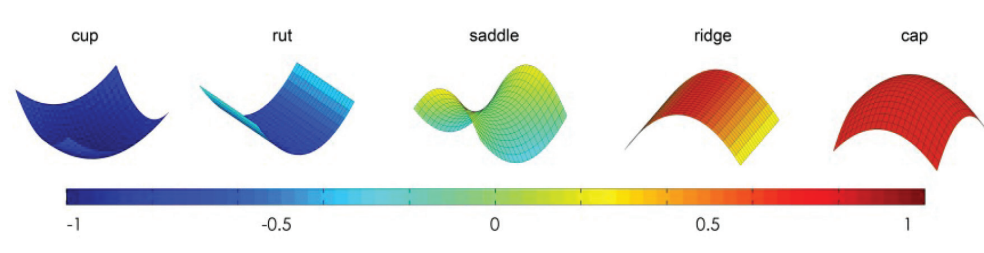

Figure 3: The surface morphology in the range of Shape Index. 
where $\mathrm{T}_{L S T}$ is the LST as the response or dependent variable, $\mathbf{X}$ is the vector of multiple explanatory or independent variables, $\beta$ is the regression coefficient indicating the relationship between the $\mathrm{T}_{L S T}$ and $\mathbf{X}$, and $e$ is the intrinsic residual.

\section{RESULTS}

\subsection{The classification of climate zones}

By applying the K-means clustering for sufficient repetitions, a 7-category classification is found to be best suited for the study area, which means that the classification is neither complicated nor simple. Figure 4 is an illustration of the classification. The shape of the climate zones outlines the distribution of a built environment meaning that artificial manipulation of land surface imposes significant impacts on climate. The details of the land surface indicator specifications are listed in Table 1. All indicators are normalized to the percentage level. The means of ISF, BD, and BVD increase along LCZ 1 through 7 implying that the artificial

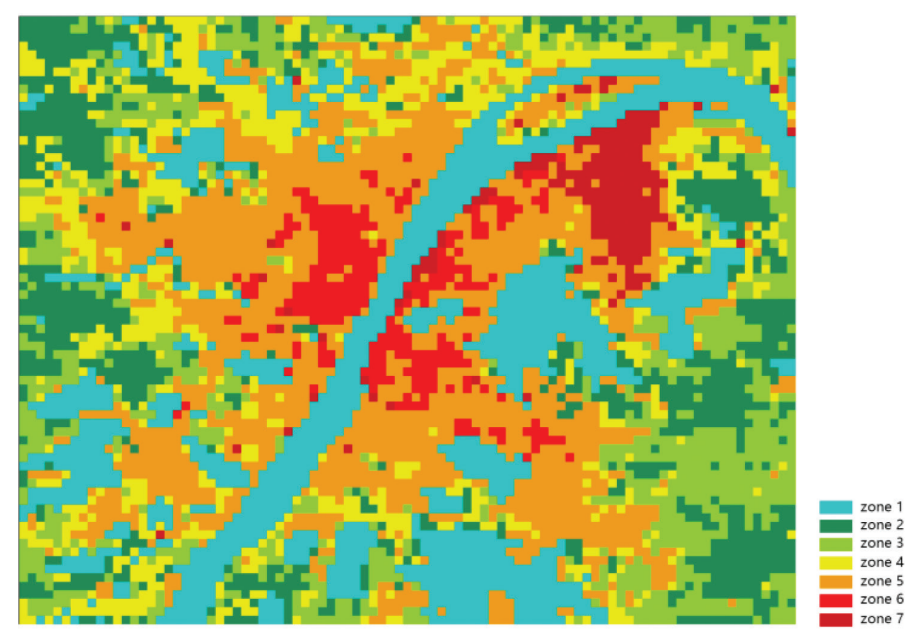

Figure 4: An illustration of the classification.

Table 1: The mean of the land surface indicator specifications in each of the LCZs (\%).

\begin{tabular}{llllllllll}
\hline $\mathbf{L C Z}$ & SVF & BD & BVD & BH & PSF & Albedo & VI & ISF & WI \\
\hline $\mathbf{1}$ Water Bodies & 99.52 & 2.28 & 1.60 & 4.03 & 81.21 & 17.48 & 4.57 & 6.51 & 58.16 \\
$\mathbf{2}$ Vegetation & 99.71 & 3.43 & 1.92 & 5.60 & 71.68 & 22.64 & 38.26 & 10.07 & 21.95 \\
$\mathbf{3}$ (Vegetation and & 99.80 & 2.50 & 1.20 & 5.88 & 78.55 & 24.75 & 38.14 & 8.99 & 11.42 \\
$\quad$ rural areas) & & & & & & & & & \\
$\mathbf{4}$ (Rural Areas) & 99.17 & 7.99 & 3.57 & 5.61 & 66.89 & 22.69 & 28.75 & 16.94 & 22.50 \\
$\mathbf{5}$ (Built-up Areas) & 94.83 & 15.36 & 14.58 & 12.21 & 71.17 & 23.35 & 25.20 & 25.31 & 15.95 \\
$\mathbf{6}$ (Downtown) & 83.92 & 29.21 & 42.91 & 18.78 & 52.59 & 20.29 & 17.17 & 43.61 & 20.35 \\
$\mathbf{7}$ (Industrial District) & 99.14 & 18.70 & 7.59 & 6.26 & 51.15 & 20.66 & 18.74 & 39.98 & 22.59 \\
\hline
\end{tabular}


modification of natural environment intensifies. The increase of $\mathrm{BH}$ is pre-eminent in LCZ 5 and 6 as high-rise residential communities and office buildings are clustered in downtown within these LCZs. The traditional low-rise and dense residential communities also enhance BD and BVD in LCZ 6. These dense buildings and apartments also substantially block visible sky and make LCZ 6 the only zone with SVF below 90\%. Those indicators such as VI, PSF, and WI depicting the abundance of natural land surface decrease from LCZ 1 to 7 only except for the deficiency of VI in water bodies of LCZ 1. Albedo is roughly uniform along all LCZs with values around 23\%. The traditional deteriorating communities and factory buildings with dark roofs lead to lower albedo in LCZ 6 and 7. The albedo values are $20.34 \%$ and $20.60 \%$, respectively.

For the convenience of cross-sectional comparison among LCZs, the mean values in Table 1 are plotted column-wise (Fig. 5). Same indicators in each of the seven LCZs are compared based on the overall mean of the study area. BD, BVD, PSF, ISF, and VI exhibit more prominent opposite deviations from the overall mean for rural and built-up areas.

\subsection{The situation of LSUHI around one year}

Figure 6a gives the frequencies of being LSUHI at each pixel location for all of the 48 time points. The LSUHIs with high frequency are distributed across the whole study area, especially in the southwest. These areas with serious thermal environment problems are called Wuhan Economic \& Technological Development Zone in the southwest, Jinyin Lake Industrial Zone in the northwest, and WISCO Industrial Zone in the northeast. Then, the central area is mainly alongside the Yangtze River and lies at the north of the Ink Lake. To the southwest, the LSUHIs in a developed industrial zone are more apparent thanks to the
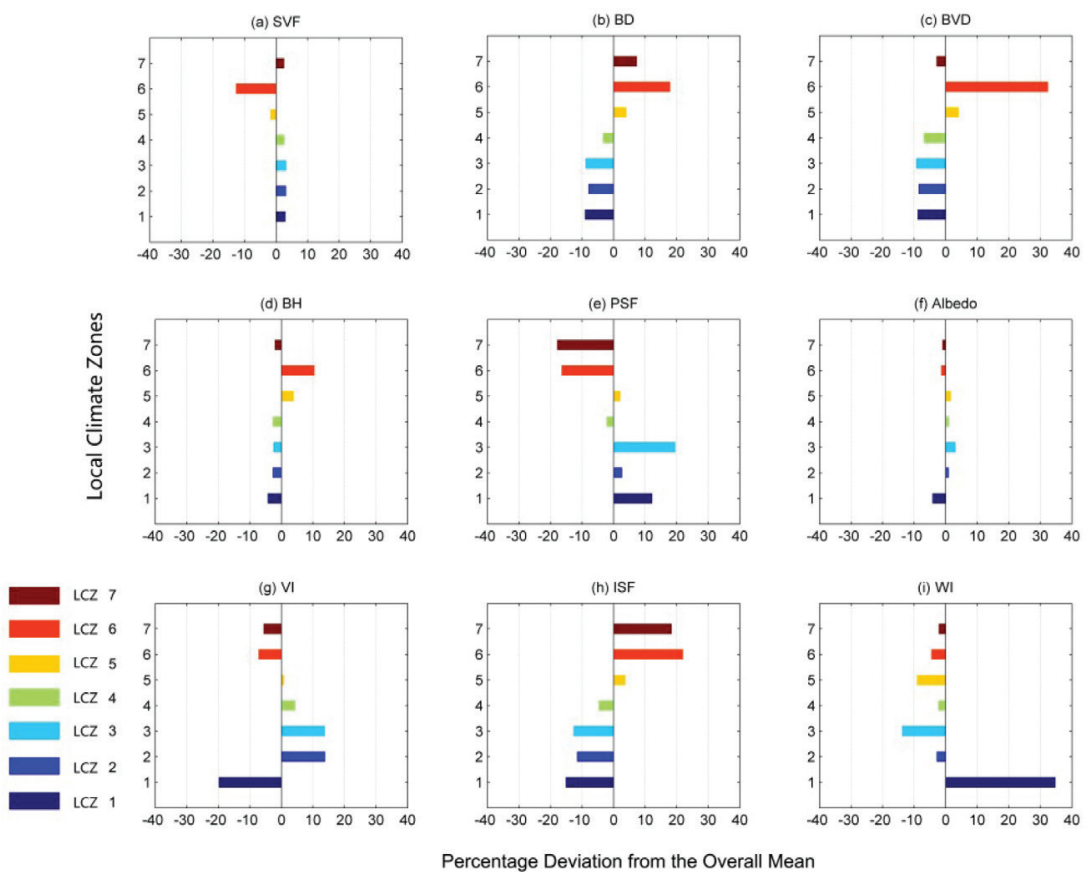

Figure 5: Comparison of LCZs in terms of indicators. 

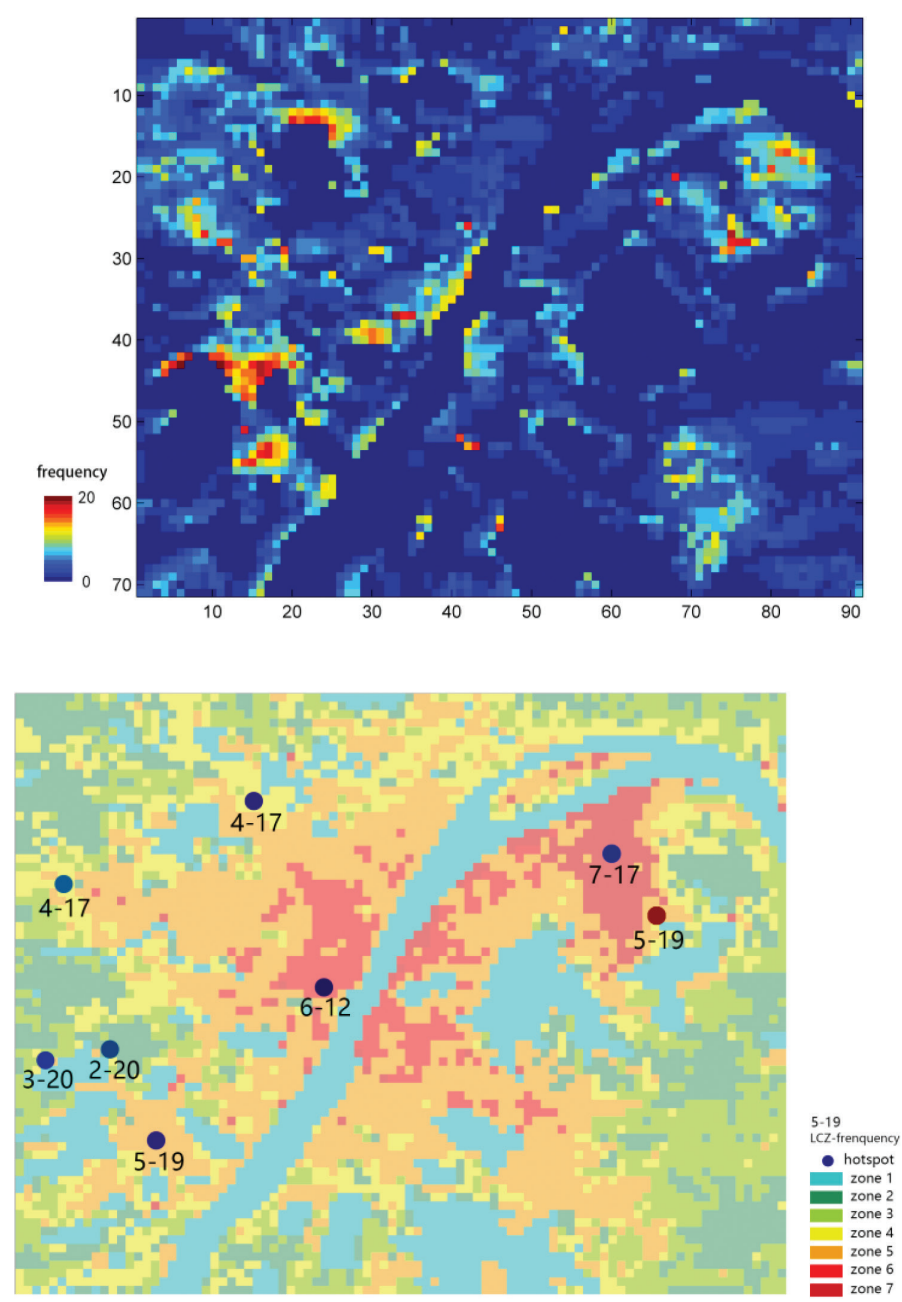

Figure 6: (a) The frequency distribution of LSUHI and (b) the selected hotspots in each LCZ (5-19: LCZ-LSUHI frequency), and the red hotspot is selected as the example in this case study.

development of low intensity. It can be found that the LSUHIs with high frequency are mainly industrial zones around the city and urban center with dense population. Eight hotspots are selected with the highest frequency as the LSUHI in LCZs.

\subsection{The land surface-LST interactions}

Table 2 shows the impacts of the land surface indicators on LST in each LCZ at the pixel level in this research, which are all statistically significant $(p>0.01)$. Take the ISF-LST relationship for instance, the regression coefficient $\beta$ varies across zones in different places and scales. While a previous study has found that the coefficient is around $0.21^{\circ} \mathrm{C}$ in the whole study area [10], the table shows that the zonal coefficient fluctuates around this value. Higher 
Table 2: The interactions between the land surface indicators and LST in each LCZ.

\begin{tabular}{lllllllll}
\hline $\begin{array}{l}\text { Multi-variable } \\
\text { OLS Regression } \\
\text { Parameters }\end{array}$ & Indicators LCZ 1 & LCZ 2 & LCZ 3 & LCZ 4 & LCZ 5 & LCZ 6 & LCZ 7 \\
\hline$\beta$ & SVF & -0.040 & -0.032 & -0.037 & -0.015 & -0.004 & -0.001 & -0.005 \\
& BD & 0.025 & 0.039 & 0.082 & 0.067 & 0.061 & -0.064 & 0.148 \\
& BVD & 0.013 & 0.003 & 0.014 & 0.067 & -0.023 & -0.027 & 0.227 \\
& BH & 0.064 & 0.017 & 0.002 & 0.036 & 0.001 & -0.006 & 0.204 \\
& Albedo & -0.325 & -0.014 & -0.019 & -0.026 & -0.107 & -0.247 & -0.226 \\
& VI & -0.062 & -0.082 & -0.109 & -0.093 & -0.142 & -0.097 & -0.196 \\
& WI & -0.116 & -0.076 & -0.110 & -0.079 & -0.033 & -0.024 & -0.023 \\
$\mathbf{R}^{2}$ & & 0.761 & 0.566 & 0.494 & 0.708 & 0.667 & 0.778 & 0.583 \\
$\boldsymbol{p}$ & & $* *$ & $* *$ & $* *$ & $* *$ & $* *$ & $* *$ & $* *$ \\
\hline
\end{tabular}

\section{Single-variable}

OLS Regression

Parameters

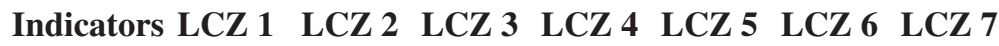

\begin{tabular}{lccccccccc}
\hline$\beta$ & ISF & 0.390 & 0.440 & 0.227 & 0.185 & 0.188 & 0.190 & 0.192 \\
$\mathbf{R}^{2}$ & & 0.577 & 0.326 & 0.381 & 0.687 & 0.704 & 0.752 & 0.780 \\
$\boldsymbol{p}$ & & $* *$ & $* *$ & $* *$ & $* *$ & $* *$ & $* *$ & $* *$ \\
\hline
\end{tabular}

** indicates $p>0.01$ and thus the relationship is statistically significant with a confidence level of $99 \%$

values are found in zone 1 and 2. It means that LST is more sensitive to ISF change in these well-vegetated LCZs with lower ISF. For instance, increasing 1\% of ISF in LCZ 1 may cause LST to rise to about $0.39^{\circ} \mathrm{C}$ within a pixel. The coefficient $\beta$ tends to be smaller in LCZ 3 to 7, which means that the change of the ISF in built-up areas imposes less impact on LST. In contrast, ISF increasingly captures information of LST variations toward more intensive built-up LCZs according to the $\mathrm{R}^{2}$. Specifically, the $\mathrm{R}^{2}$ rises from 0.33 to 0.78 through LCZ 2 to 7 . It means that although LST is less sensitive to the change of ISF, such seemingly weak interactions may dominate the LST patterns as built-up areas are mostly impervious.

The multi-variable OLS regression suggests that SVF, albedo, VI, and WI are negatively correlated to LST while BD, BVD, and BH possess less clear relationships to LST. Especially for those more intensively built LCZs, BD, BVD, and $\mathrm{BH}$ can be negatively correlated to the LST which seems to be counterintuitive. A previous study has shown that this is because urban surface can be well shaded by high and dense building clusters and thus with lower surface temperature [28]. Although SVF maintains to be negatively correlated to LST in LCZ 5,6 , and 7, its impact tends to be minimal and below -0.01. Among all the indicators involved in the multi-variable regression, albedo and VI possess the highest regression coefficients with LST. The $\mathrm{R}^{2}$ is relatively low in LCZ 2 and 3 for both the multi-variable and singlevariable regressions. Such low $\mathrm{R}^{2}$ reflects the limitation of using several built environment indicators in the interpretation of the LST variation in rural areas. 


\subsection{The strategy to mitigate the hotspots}

The hotspot as a study case is located in the northeast of the city in LCZ 5 with a frequency of 19 as being LSUHI. The hotspot is near the Yanxi Lake and lies at the southeast of the WISCO Industrial District. The overall mean of the study area is the benchmark. The largest discrepancy between the hotspot and LCZ is found in BD with $54.05 \%$. The indicator specifications at this hotspot are mostly less desirable than the level of LCZ 5, while this LCZ is a less desirable zone in the study area (Fig. 7a). The counterintuitive negative relationship between LST and BVD makes the strategy relatively subtle. The buildings are dense enough to shade the land surface as mentioned in Section 3.3. Thus, modification of building geometries may be less promising. Indicators such as PSF, albedo, VI, ISF, and WI are all clearly indicated in Fig. 5. These indicator values should be first modified to the zonal level and not the average level of the study area based on priority. Considering the relationships between the land surface indicators and LST, increasing $1 \%$ of albedo may reduce $0.11^{\circ} \mathrm{C}$ of LST at
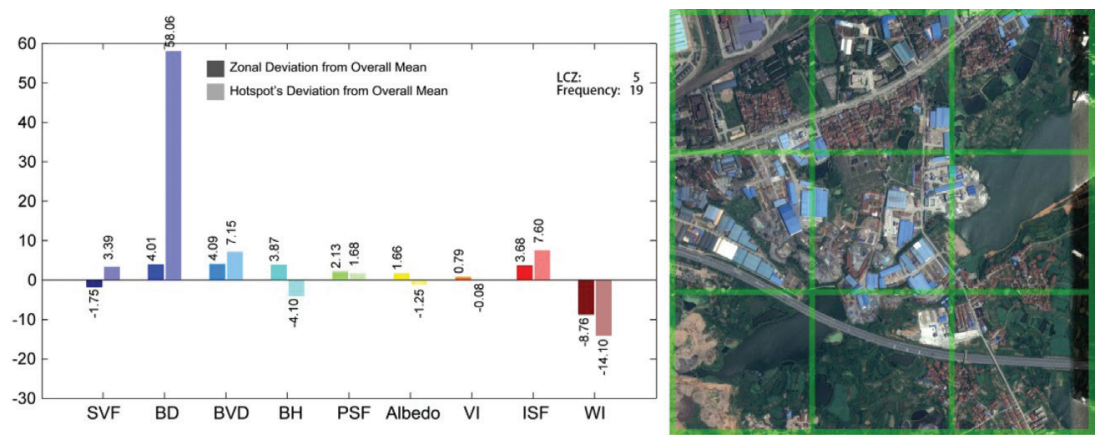

Figure 7: The land surface indicator specifications of hotspot and LCZ 5. (a) The indicator discrepancy between the hotspot and the LCZ benchmarked against the overall mean of the study area. (b) The QuickBird aerial image of the hotspot with its eight neighboring pixels on May 20th, 2012.

Table 3: The indicator values of hotspot and mean of indicator for LCZ 5.

\begin{tabular}{|c|c|c|c|c|c|c|c|c|c|}
\hline & SVF & BD & BVD & BH & PSF & Albedo & VI & ISF & WI \\
\hline $\begin{array}{l}\text { mean of the study } \\
\text { area }\end{array}$ & 97.56 & 8.57 & 7.43 & 7.72 & 61.07 & 21.89 & 27.61 & 16.70 & 26.53 \\
\hline hotspot & 99.98 & 69.41 & 17.63 & 4.24 & 70.71 & 22.45 & 17.41 & 29.23 & 10.60 \\
\hline LCZ 5 & 94.83 & 15.36 & 14.58 & 12.21 & 71.17 & 23.35 & 25.20 & 25.31 & 15.95 \\
\hline $\begin{array}{l}\text { Hotspot-LCZ } \\
\text { Discrepancy }\end{array}$ & 5.15 & 54.05 & 3.05 & -7.97 & -0.46 & -0.90 & -7.79 & 3.92 & -5.35 \\
\hline $\begin{array}{l}\text { Surface-Temperature } \\
\text { Relationship }\end{array}$ & -0.004 & 0.061 & -0.023 & 0.001 & - & -0.107 & -0.142 & 0.188 & -0.033 \\
\hline $\begin{array}{l}\text { Potential } \\
\text { Optimization }\left({ }^{\circ} \mathrm{C}\right)\end{array}$ & - & - & - & - & - & 0.10 & 1.11 & 0.74 & - \\
\hline
\end{tabular}


the pixel level. It means that if albedo at hotspot increases by $0.9 \%$ to reach the corresponding zonal level, LST can potentially be $0.1^{\circ} \mathrm{C}$ lesser. Similarly, modifying VI to the zonal level can reduce 1.11 of LST in a pixel. Approximating ISF at the hotspot to the zonal level leads to a reduction of $0.74^{\circ} \mathrm{C}$. The details are shown in Table 3 . In a word, the indicator values of hotspot are adjusted to an approximate mean of the indicator for LCZ 5 to relieve LSUHI.

As this study focuses on the concept and framework, further examples are not explored. The mitigation strategies for other hotspots can be formulated in the same way as shown above.

\section{DISCUSSION}

\subsection{The completeness and dynamic of indicators}

The completeness of indicators means to characterize the climatic or meteorological property of the surface factor with enough details. Besides thermal and airflow pattern, others such as humidity, moisture, and pollution are also expected to be captured by the indicators. Only then can the indicators be considered to be complete.

The hotspot is selected from a one-year cycle without considering the diurnal or seasonal variation of land surface specification. The dynamic difference of these indicators would affect the distribution of LSUHI. More specific improvement strategies and suggestions would be proposed, if the distribution of the hotspots is further explored with land use and diurnal variation of indicators being taken into account.

\subsection{The priority of planning and implementation}

This research only adjusted the land surface parameters, whereas specific implementation approaches are different when carrying out the adjustment. The complexity and cost of each strategy is different in terms of planning and implementation. For example, the cost of reducing building density is normally higher than that of increasing vegetation cover. Meanwhile, the complexities in mitigation strategies also vary because of land use variance. The vegetation cover of public land is usually easier to adjust than that of residential land. The hotspot with high population density should be taken into consideration at day one, especially in urban centers. The high-frequency LSUHIs in city suburbs are mostly industrial zones, regarded as a secondary consideration due to low population density. It is therefore reasonable to say that the priority of planning strategy should be considered in terms of land use, population density, complexity of adjusting specifications, and the correlation between the indicators and LST.

\section{CONCLUSIONS}

A framework of mitigating excessive heat in urban areas is proposed. The mitigation is at a local scale and helps to facilitate planning and design strategy selection with detailed guidelines. The mitigation is operated within zones and conforms to planning and design conventions. It avoids radical modifications of land surface configuration and enhances feasibility and practicability. The mitigation thus attenuates in a hierarchical and incremental manner. The hierarchy manifests by priority based on two aspects: (1) problem identification, and (2) strategy recommendation. The incrementality is reflected by zonal level mitigation that ensures more achievable goals. 


\section{ACKNOWLEDGMENT}

This research is supported by the National Natural Science Foundation of China (No.51378399 and No.41331175).

\section{REFERENCES}

[1] Stone, B., Vargo, J. \& Habeeb, D., Managing climate change in cities: will climate action plans work? Landscape and Urban Planning, 107(3), pp. 263-271, 2012. https://doi.org/10.1016/j.landurbplan.2012.05.014

[2] Brian Stone, J. \& Michael, O.R, Urban form and thermal efficiency: how the design of cities influences the Urban Heat Island effect. Journal of the American Planning Association, 67(2), pp. 186-198, 2001.

https://doi.org/10.1080/01944360108976228

[3] Debbage, N. \& Shepherd, J.M., The urban heat island effect and city contiguity. Computers, Environment and Urban Systems, 54, pp. 181-194, 2015. https://doi.org/10.1016/j.compenvurbsys.2015.08.002

[4] Wheeler, S., State and municipal climate change plans: the first generation. Journal of the American Planning Association, 74(4), pp. 481-496, 2008. https://doi.org/10.1080/01944360802377973

[5] Stewart, I.D., A systematic review and scientific critique of methodology in modern urban heat island literature. International Journal of Climatology, 31(2), pp. 200-217, 2011. https://doi.org/10.1002/joc.2141

[6] Arnfield, A.J., Two decades of urban climate research: a review of turbulence, exchanges of energy and water, and the urban heat island. International Journal of Climatology, 23(1), pp. 1-26, 2003. https://doi.org/10.1002/joc.859

[7] Stewart, I.D. \& Oke, T.R., Local climate zones for urban temperature studies. Bulletin of the American Meteorological Society, 93(12), pp. 1879-1900, 2012. https://doi.org/10.1175/BAMS-D-11-00019.1

[8] Yuan, F. \& Bauer, M.E., Comparison of impervious surface area and normalized difference vegetation index as indicators of surface urban heat island effects in Landsat imagery. Remote Sensing of Environment, 106(3), pp. 375-386, 2007. https://doi.org/10.1016/j.rse.2006.09.003

[9] Song, J., Du, S., Feng, X. \& Guo, L., The relationships between landscape compositions and land surface temperature: Quantifying their resolution sensitivity with spatial regression models. Landscape and Urban Planning, 123, pp. 145-157, 2014. https://doi.org/10.1016/j.landurbplan.2013.11.014

[10] Wang, J., Qingming, Z., Guo, H. \& Jin, Z., Characterizing the spatial dynamics of land surface temperature-impervious surface fraction relationship. International Journal of Applied Earth Observation and Geoinformation, 45, pp. 55-65, 2016. https://doi.org/10.1016/j.jag.2015.11.006

[11] Myneni, R.B., Maggion, S., Iaquinta, J., Privette, J.L., Gobron, N., Pinty, B., Kimes, D.S., Verstraete, M.M. \& Williams, D.L., Optical remote-sensing of vegetation - modeling, caveats, and algorithms. Remote Sensing of Environment, 51(1), pp. 169-188, 1995. https://doi.org/ 10.1016/0034-4257(94)00073-V

[12] Schaaf, C.B., Gao, F., Strahler, A.H., Lucht, W., Li, X., Tsang, T., Strugnell, N.C., Zhang, X., Jin, Y., Muller, J.P. \& Lewis, P., First operational BRDF, albedo nadir 
reflectance products from MODIS. Remote Sensing of Environment, 83(1-2), pp. 135148, 2002.

https://doi.org/10.1016/S0034-4257(02)00091-3

[13] Larsen, L., Urban climate and adaptation strategies. Frontiers in Ecology and the Environment, 13(9), pp. 486-492, 2015.

https://doi.org/10.1890/150103

[14] Chudnovsky, A., Ben-Dor, E. \& Saaroni, H., Diurnal thermal behavior of selected urban objects using remote sensing measurements. Energy and Buildings, 36(11), pp. 1063-1074, 2004. https://doi.org/10.1016/j.enbuild.2004.01.052

[15] Unger, J., Intra-urban relationship between surface geometry and urban heat island: review and new approach. Climate Research, 27(3), pp. 253-264, 2004. https://doi.org/10.3354/cr027253

[16] Giannopoulou, K., et al., The impact of canyon geometry on intra urban and urban: suburban night temperature differences under warm weather conditions. Pure and Applied Geophysics, 167(11), pp. 1433-1449, 2010. https://doi.org/10.1007/s00024-010-0099-8

[17] Weng, Q.H., Lu, D.S. \& Schubring, J., Estimation of land surface temperature-vegetation abundance relationship for urban heat island studies. Remote Sensing of Environment, 89(4), pp. 467-483, 2004. https://doi.org/10.1016/j.rse.2003.11.005

[18] Wu, H., Ye, L.P., Shi, W.Z. \& Clarke, K.C., Assessing the effects of land use spatial structure on urban heat islands using HJ-1B remote sensing imagery in Wuhan, China. International Journal of Applied Earth Observation and Geoinformation, 32, pp. 6778, 2014. https://doi.org/10.1016/j.jag.2014.03.019

[19] Norton, B.A., Coutts, A.M., Livesley, S.J., Harris, R.J., Hunter, A.M. \& Williams, N.S., Planning for cooler cities: a framework to prioritise green infrastructure to mitigate high temperatures in urban landscapes. Landscape and Urban Planning, 134, pp. 127-138, 2015. https://doi.org/10.1016/j.landurbplan.2014.10.018

[20] Schwarz, N., Schlink, U., Franck, U. \& Großmann, K., Relationship of land surface and air temperatures and its implications for quantifying urban heat island indicators - an application for the city of Leipzig (Germany). Ecological Indicators, 18, pp. 693-704, 2012.

https://doi.org/10.1016/j.ecolind.2012.01.001

[21] Stewart, I.D., Oke, T.R. \& Krayenhoff, E.S., Evaluation of the 'local climate zone' scheme using temperature observations and model simulations. International Journal of Climatology, 34(4), pp. 1062-1080, 2014. https://doi.org/10.1002/joc.3746

[22] Lelovics, E., Unger, J. \& Gál, T., Design of an urban monitoring network based on local climate zone mapping and temperature pattern modelling. Climate Research, 60(1), pp. 51-62, 2014. https://doi.org/10.3354/cr01220

[23] Voogt, J.A. \& Oke, T.R., Thermal remote sensing of urban climates. Remote Sensing of Environment, 86(3), pp. 370-384, 2003. https://doi.org/10.1016/S0034-4257(03)00079-8 
[24] Streutker, D.R., A remote sensing study of the urban heat island of Houston, Texas. International Journal of Remote Sensing, 23(13), pp. 2595-2608, 2002. https://doi.org/10.1080/01431160110115023

[25] Rajasekar, U. \& Weng, Q.H., Urban heat island monitoring and analysis using a nonparametric model: A case study of Indianapolis. Isprs Journal of Photogrammetry and Remote Sensing, 64(1), pp. 86-96, 2009. https://doi.org/10.1016/j.isprsjprs.2008.05.002

[26] Rasmussen, C.E. \& Nickisch, H., Gaussian Processes for Machine Learning (GPML) Toolbox. Journal of Machine Learning Research, 11, pp. 3011-3015, 2010.

[27] Gál, T., Lindberg, F. \& Unger, J., Computing continuous sky view factors using 3D urban raster and vector databases: comparison and application to urban climate. Theoretical and Applied Climatology, 95(1-2), pp. 111-123, 2008. https://doi.org/10.1007/s00704-007-0362-9

[28] Zhan, Q., Meng, F. \& Xiao, Y., Exploring the relationships of between land surface temperature, ground coverage ratio and building volume density in an urbanized environment. ISPRS - International Archives of the Photogrammetry, Remote Sensing and Spatial Information Sciences, XL-7/W3, pp. 255-260, 2015. https://doi.org/10.5194/isprsarchives-XL-7-W3-255-2015

[29] Chen, X.-L., Zhao, H.M., Li, P.X. \& Yin, Z.Y., Remote sensing image-based analysis of the relationship between urban heat island and land use/cover changes. Remote Sensing of Environment, 104(2), pp. 133-146, 2006. https://doi.org/10.1016/j.rse.2005.11.016

[30] Koenderink, J.J. \& Vandoorn, A.J., Surface shape and curvature scales. Image and Vision Computing, 10(8), pp. 565-565, 1992. https://doi.org/10.1016/0262-8856(92)90076-F

[31] Lindeberg, T., Feature detection with automatic scale selection. International Journal Of Computer Vision, 30(2), pp. 79-116, 1998. https://doi.org/10.1023/A:1008045108935

[32] Wang, J., Zhan, Q. \& Guo, H., The morphology, dynamics and potential hotspots of land surface temperature at a local scale in urban areas. Remote Sensing, 8(1), p. 18, 2015. https://doi.org/10.3390/rs8010018 